\title{
Consumption and youth employment - impact on production of Bulgarian organic products
}

\author{
Georgi ALEKSIEV, Dora DONCHEVA, Konstantin STOYANOV, Konstantin \\ STANKOV
}

Trakia University, Stara Zagora, Bulgaria

\begin{abstract}
:
During the current planning period of the Common Agricultural policy of the European Union, a newly formed Bulgarian organic production sector has rapidly developed. In the span of just three years from 2014 to 2017 Bulgaria has risen to the top of the EU organic production charts for several products (mainly aromatic oils and honey). This was in part a result of a significant institutional support from CAP and the local government. The production has grown rapidly but the same cannot be said about the local organic food market. Consumers have severe reservations towards organic products, their higher prices and lack of confidence towards their quality and certification.
\end{abstract}

Aim: To analyze the dynamics of production of Bulgarian organic products and the local organic food market in order to assess its sustainability.

Design/Research methods: The methods used to solve the tasks are: analysis and synthesis, systematic and structural approach, statistical calculations. This study analyzes data from centralized sources as well as from own research.

Conclusions/findings: There is still not enough bio-food processing plants in the country and with the necessary capacity to meet the local market needs. This has led to a clear export orientation of local bio products. Over the last two years, the construction and certification of processing facilities in the sector have begun and they are most often the result of foreign investment. Adding value to Bulgarian bio products is important for their recognition and trust by local consumers as well as those on international markets.

Originality/value of the article: The underlined correlation between production and consumption of organic products in Bulgaria has never been fully researched.

Keywords: bio-products, market, support, competitiveness JEL: Q01, Q10, Q13

Correspondence address: Georgi ALEKSIEV, Dora DONCHEVA, Konstantin STOYANOV, Konstantin STANKOV, Trakia University, Stara Zagora, Bulgaria. E-mail:

Received: 28.06.2018, Revised: 22.02.2019, Accepted: 24.02.2019 doi: http://dx.doi.org/10.29015/cerem.746 


\section{Introduction}

The organic production in Bulgaria outpaces the local market growth. The majority (over $80 \%$ ) of the organic production is exported - mainly on the European market - mostly in Germany, the Netherlands, France, and Italy. There are also exports to the USA, Japan, Korea and Canada. Bulgaria is one of the largest exporters of wild dried berries and herbs. Frozen fruits - strawberries, raspberries and blueberries, organic honey, essential oils of rose, lavender, mint, cheese, yellow cheese and jams are being exported and received very well on the international market (Kostadinova, Popov 2012). Bulgarian organic products are competitive on international markets due to their quality and lower prices, as well as meeting all requirements and standards and being unique in some cases (Kristeva 2014).

Although organic farming in Bulgaria is at an early stage of its development, the trends are ascending for the last 10 years and it is developing at a rapid pace. With the launch of the new Bulgarian Rural Development Program (RDP) for the 20142020 period, the expectations for the development of organic farming are increasing, as the EU funding for organic farming is increased 5 times (from EUR 33 million in the previous RDP to EUR 152 million in the new one). For the first time, funding for organic livestock farming is also planned, and measures such as pastoralism (seasonal grazing), conservation of endangered local breeds and other activities are also under funding. This measure allows the organic farming model to be established as an effective solution to small and medium-size businesses for increasing their competitiveness, as well as to maintain employment and create jobs to generate growth in rural areas.

Production of organic foods as a specific part of the agricultural sector has higher requirements regarding the technology and techniques in such enterprises which is better suited for young, flexible entrepreneurs. The results of current study have led the authors to the conclusion that this newly forming sector (organic food production) creates unique opportunities for which younger entrepreneurs are better prepared. 
The paper is organized as follows: Section 2 describes used materials, methods and data sources. Section 3 presents the results and discussions splits into three parts and Section 4 concludes this paper.

\section{Material and methods}

The study makes an analysis of the dynamics of production of Bulgarian organic products and the local organic food market in order to assess its sustainability and also, presents a brief overview about youth employment. For the analyses in the paper is used an information about organic production in Bulgaria provided by the Ministry of Agriculture and Food of the Republic of Bulgaria - MAF (Ministry of Agriculture and Food of the Republic of Bulgaria 2017) which is based on data from the annual reports of organic production certification companies officially approved by the MAF. Also, this study analyzes data from centralized sources as well as from own research. The methods used to solve the tasks are: analysis and synthesis, systematic and structural approach, statistical calculations.

\section{Results and discussions}

\subsection{Production of Bulgarian organic products}

Organic has become a way of living (Rossi 2016). Many people have become seen these products as being healthier or tastier than their conventional equivalents, others appreciate good production practices and sustainable job opportunities.

According data from FiBL and IFOAM (Willer, Lernoud 2018), the development of the European Union's organic sector in 2016 was characterized by two trends. On the one hand, the market showed a double-digit growth rate again $(12 \%)$. On the other hand, organic farmland growth continued to be slower than that of the market, but it was considerably faster than the previous years. The trend of the market growing at a faster rate than the area has been occurring for several years, showing that production is still not keeping pace with consumer demand. 
Organic farming in Bulgaria is at an early stage of its development, but the trends are ascending and it is developing at a rapid pace. For the period 2006-2017, the number of organic operators and areas in organic production has increased by more than 12 times, the number of cattle and bee families has increased 7 times, about 10 times for the number of sheep and more than 25 times for the number of goats.

When reviewing registered operators in the control system, it is noted that registered organic breeders are also registered as pasture holdings. This requirements underlying both regulations allows us to analyze the correlation between the pastures in the control system and the livestock units.

Table 1. Number of processors of organic products, 2008-2015

\begin{tabular}{|l|c|c|c|c|c|c|c|c|c|}
\hline \multicolumn{1}{|c|}{ Type of processors } & $\mathbf{2 0 0 8}$ & $\mathbf{2 0 0 9}$ & $\mathbf{2 0 1 0}$ & $\mathbf{2 0 1 1}$ & $\mathbf{2 0 1 2}$ & $\mathbf{2 0 1 3}$ & $\mathbf{2 0 1 4}$ & $\mathbf{2 0 1 5}$ & $\mathbf{2 0 1 6}$ \\
\hline $\begin{array}{l}\text { Certified } \\
\text { manufacturers of } \\
\text { organic foods }\end{array}$ & - & - & - & - & - & - & - & 250 & 253 \\
\hline $\begin{array}{l}\text { Processors of fruits } \\
\text { and vegetables }\end{array}$ & 16 & 29 & 21 & 22 & 29 & 21 & 20 & 45 & 54 \\
\hline Processors of grains & 0 & 1 & 2 & 2 & 2 & 0 & 1 & 24 & 23 \\
\hline $\begin{array}{l}\text { Processors of dairy } \\
\text { products }\end{array}$ & 3 & 3 & 5 & 7 & 7 & 9 & 14 & 26 & 29 \\
\hline $\begin{array}{l}\text { Processors of meat } \\
\text { products }\end{array}$ & 0 & 0 & 0 & 0 & 0 & 1 & 1 & 5 & 0 \\
\hline $\begin{array}{l}\text { Processors of bakery } \\
\text { products }\end{array}$ & 0 & 0 & 0 & 1 & 8 & 4 & 10 & 20 & 20 \\
\hline $\begin{array}{l}\text { Processors of other } \\
\text { foods }\end{array}$ & 10 & 13 & 16 & 9 & 26 & 45 & 70 & 83 & 95 \\
\hline $\begin{array}{l}\text { Processors of } \\
\text { beverages }\end{array}$ & 0 & 0 & 0 & 0 & 6 & 6 & 15 & 22 & 21 \\
\hline Processors of wine & 0 & 0 & 0 & 0 & 5 & 2 & 4 & 14 & 17 \\
\hline
\end{tabular}

Source: Eurostat.

By 2016, the organic food processing sector in Bulgaria is still underdeveloped and this is one of the reasons for the low levels of supply of local bio foods. The change in this trend is observed at the end of 2015 and early 2016, when the number of processors increased slightly, largely due to EU-subsidized investments and increased consumer demand (see Table 1). Although there is no significant increase, a concentration of the organic production is evident. After the initial period of 
adjustment producers realized the competitive advantages of certain sub-sectors and focused their attention on those (organic wine production, production of processed organic fruit foods and some organic dairy products). The main processed products are yogurt, cheese, honey, bakery products, wine, herbs and tea.

The institutional support for organic livestock breeding in Bulgaria is embodied in the Ordinance № 4 of 24.02.2015, developed by the Bulgarian Ministry of Agriculture and Food, for the implementation of Measure 11 "Organic farming" of RDP for the period 2014-2020. It describes both the requirements for bio-producers, as well as the shape and size of support for individual crops and livestock. Areas in the control system have significant growth, which does not reflect in growth of the number of organically bread animals. This is due to the requirements set by Ordinance № 1 and Ordinance № 4 of the Ministry of Agriculture and Foods for the existence of a minimum volume of grazing areas for the organic farming of livestock.

Based on our own calculations and analysis of the biologically assimilated livestock units available in 2015 amounting to $7654 \mathrm{LU}$ and permanent meadows and pastures with a total area of 31796 ha we can conclude that the development of organic pastures in Bulgaria allows to maintain the rate of development of organic livestock farming in the country, with the free base for support in the sector under this criterion being above $75 \%$. The exclusion of organic beekeeping from the calculations and analysis made is based on the presence of significant areas with wild vegetation in the control system, which are more often used by farmers for organic apiculture in the country.

The main crops grown biologically in Bulgaria are arable crops (cereals, green fodder and technical crops); perennials (fruit trees, berries, olives and vines) and meadows and pastures.

The rate of increase of the areas in the control system exceeds the growth rate of the number of operators in organic production in the period from 2006 to 2013 due to the slower reaction of a part of the current producers and processors to the specific requirements of this type of production. The increase in the number of holdings included in the organic livestock control system also has impact on this 
process which due to the specificity of some of its sub-sectors does not require the existence of significant areas for the development of production.

The aggravation of the Bulgarian agrarian sector and the specialization in the production of grain and technical crops determine the leading role of big farms. This contributes to the small share of organic farms in the country's total agrarian production. Strict regulatory requirements do not allow the deployment of largescale organic farms, and in some cases the legal framework makes this absolutely impossible. Due to this fact, there are a number of problems in organic farming for small agrarian farms - the regulated possibilities for direct supply of small quantities of raw materials and food products cannot have a significant positive effect on small farms as the requirements imposed imply significant additional costs (Balieva, Huliyan 2015).

Despite all the problems noted here, the biological production in Bulgaria marks a fast pace of development, which places Bulgaria at seventh place in the world in terms of the area grown according to the requirements for organic production, according to data from FiBL and IFOAM (2015).

\subsection{Consumption of Bulgarian organic products}

The improved economic situation in the country and an increase in average incomes in 2014-2015 encourage the growing interest in and popularity of healthy eating habits and lead to increased consumption of organic food. Current market trends can be summarized in several key points:

- The market breakthrough in the 2014-2015 was based on it including not only the high-earning households looking for high-quality products but also those with average incomes who are trying to follow a healthy lifestyle and are concerned about unhealthy supplements or preservatives in traditional products.

- The concept of healthy lifestyle and the purchase of organic food has left the borders of large cities in the end of the period. Large and medium-sized cities also account for a growing group of consumers. Although buyers in major cities dominate, the penetration of regional and local markets has begun. 
- All types of retail channels show growth in sales of organic products. Improved consumer demand encourages retailers to pay more attention to organic products. The share of organic sales through this channel increased from $44.5 \%$ in 2010 to $61.4 \%$ in 2015 (see Table 2). This helps to increase consumer awareness, especially on labelling. All retail chains already have specially organized bio-food areas and some market players are making special efforts to emphasize these sales by improving the variety of organic food offered;

Table 2. Distribution of organic packaged food by format, 2013-2015

\begin{tabular}{|l|c|c|c|}
\hline Type of retail channel & $\mathbf{2 0 1 3}$ & $\mathbf{2 0 1 4}$ & $\mathbf{2 0 1 5}$ \\
\hline Grocery retailers & $98.80 \%$ & $99.00 \%$ & $99.00 \%$ \\
\hline Modern grocery retailers & $57.30 \%$ & $58.60 \%$ & $61.40 \%$ \\
\hline Convenience stores & $4.60 \%$ & $4.40 \%$ & $4.40 \%$ \\
\hline Discounters & $27.30 \%$ & $28.30 \%$ & $28.60 \%$ \\
\hline Hypermarkets & $0.80 \%$ & $0.80 \%$ & $1.00 \%$ \\
\hline Supermarkets & $23.00 \%$ & $23.60 \%$ & $26.00 \%$ \\
\hline Traditional grocery retailers & & & \\
\hline Independent small grocers & $25.20 \%$ & $23.90 \%$ & $20.90 \%$ \\
\hline Other grocery retailers & $16.3 \%$ & $16.5 \%$ & $16.8 \%$ \\
\hline Internet retailing & $0.2 \%$ & $0.2 \%$ & $0.2 \%$ \\
\hline Total & $100.0 \%$ & $100.0 \%$ & $100.0 \%$ \\
\hline
\end{tabular}

Source: Euromonitor.

- The main challenge remains the level of consumer incomes. Organic foods are often more expensive than their conventional equivalents and are considered inaccessible to many. Higher prices for organic products are a barrier to faster market penetration and rapid sales growth;

- Consumers' awareness of organic food is still not very high but remains critical for market development. Often, conventional food equivalents may have brands or subtypes that are labeled "local" or "natural" products and attract customers at a lower price than the equivalent organic product. Such "green/local/clean" labeling often misleads consumers who rarely fully read 
labels. Advertising and marketing campaigns continue to shape positive consumer attitudes;

- Factors contributing to the consumer's lack of trust in bio-products are the weaknesses of the certification system and the lack of trust in their labels. Progress in this regard was made in 2016 with an improved regulatory environment and oversight that promises better prospects for the future.

Organic food sales were estimated in 2015 at 30 million leva (\$ 17 million), up 7\% increase over 2014 (see Table 3). The growth for the last 5 years was impressive - at $73 \%$. The sales estimate for 2016 is about $\$ 31.6$ million ( $\$ 17.5$ million), or $5.3 \%$ more than in 2015, and may reach $\$ 33.3$ million (\$ 18.5 million) in 2017 (final figures for 2017 are not yet available). Organic sales levels in Bulgaria in 2020 are projected to exceed 39 million levs. This would represent a $30 \%$ increase on a five year basis (2015-2020).

Most estimates of the size of the organic food market place it at a level of $1 \%$ of the total food market, although official data fail to support this claim due to the lack of adequate reporting of organic products sales on the domestic market. Sales of organic baby food represent the largest share in sales of organic products $-36 \%$ in 2015 . Traded levels have grown by $63 \%$ more than in 2010 and by $7 \%$ more than in 2014.

The presence of well-established producers in this segment with reliable and quality products keeps the levels of demand high. The market leader in this category maintains low organic baby food prices, which are only slightly higher than conventional equivalents, and this strategy attracts an increasing number of consumers. The category of dairy products is the second largest after baby food with an $18 \%$ share of total organic food sales in 2015. In 2015, these sales were $10 \%$ more than in 2014 and 54\% more than in 2006.

The total number of different organic food stores in the country is around 2,000. The number of organic products sold on the market has increased - from 2500 in 2012 to around 4,500 in 2016. All major retailers, as well as many independent and smaller supermarkets offer organic food. 
Table 3. Sales of organic packaged foods by category, 2010-2015 (mil. \$US)

\begin{tabular}{|l|c|c|c|c|c|c|}
\hline $\begin{array}{l}\text { Category of organic packaged } \\
\text { foods }\end{array}$ & $\mathbf{2 0 1 1}$ & $\mathbf{2 0 1 2}$ & $\mathbf{2 0 1 2}$ & $\mathbf{2 0 1 3}$ & $\mathbf{2 0 1 4}$ & $\mathbf{2 0 1 5}$ \\
\hline Organic baby food & 3.7 & 3.8 & 4.9 & 5.3 & 5.6 & 6.1 \\
\hline Organic bakery products & 1.3 & 1.4 & 1.6 & 2 & 1.9 & 2.1 \\
\hline $\begin{array}{l}\text { Organic biscuits, snack bars, } \\
\text { cereals }\end{array}$ & 0.4 & 0.7 & 0.8 & 0.8 & 0.9 & 0.9 \\
\hline Organic dairy & 1.9 & 2 & 2.3 & 2.5 & 2.7 & 3 \\
\hline $\begin{array}{l}\text { Organic sauces, dressings and } \\
\text { condiments }\end{array}$ & $\mathrm{NA}$ & $\mathrm{NA}$ & $\mathrm{NA}$ & 1.4 & 1.4 & 1.4 \\
\hline Organic rice, pasta and noodles & 0.9 & 0.9 & 1.1 & 1.2 & 1.2 & 1.3 \\
\hline Organic spreads & 1 & 1 & 1.2 & 1.2 & 1.3 & 1.4 \\
\hline Organic sweet and savory snacks & 0.2 & 0.2 & 0.2 & 0.3 & 0.3 & 0.3 \\
\hline Organic packaged food & 9.6 & 10.3 & 12.05 & 14.4 & 15.5 & 16.7 \\
\hline
\end{tabular}

Source: Euromonitor.

Retail chains remain the main channel for the sale of organic packaged foods. In 2015 , they represent $61.4 \%$ of organic sales, compared to $58.6 \%$ in 2014 . The small independent retailers have made only $20.9 \%$ of the sales of organic products, with the level of this trade channel falling from 38.8\% compared to 2010.

Other retailers (specialized stores) are the third channel representing $16.8 \%$ of bio-packaged food in 2015, with the role of this channel growing. The number of specialized sites is increasing significantly and many of them are specialized in the provision of "healthy/organic lifestyle" products such as food, beverages and/or cosmetics that meet consumer demand. These stores offer the greatest variety and quality of products, have a very good market penetration and count the growing popularity.

Some of them combine organic food sales with food services, such as cafes with organic food sales, beverages and herbs. According to the Bulgarian Association of Bio-Producers in 2017, 1500 specialized stores offer bio-products. As consumer demand is still low, most of these stores offer both conventional and organic products under the general concept of "Healthy Food". Market research at the 
moment suggests that specialized stores that only offer organic products are not more than 100 in the whole country.

Another popular channel is farm markets, weekly markets or specially organized markets - for Christmas/Easter, green/bio stands or halls at trade fairs, sporting events, etc. This channel is preferred by local organic farmers and small organic farmers who cannot offer significant retail volumes and quality certification that major retailers require. Due to the growing number of these small farms who are looking for more direct contact with consumers, the role of these markets has grown and they are increasingly competing with specialized stores. This channel has been identified as ideal for promotional and marketing activities and consumer awareness campaigns.

\subsection{Impact of the local production, processing and trade of organic product on youth employment in Bulgaria}

As mentioned above, organic farming is developing successfully in the last decade in comparison to other European countries. The main factors for this developments are good soil and climatic conditions in Bulgaria, lack of polluting industrial complexes for more than 20 years; a good level of education, training and scientific research activities; implementation of projects for lifelong learning and vocational training in the field of organic production, management and trade (UARD 2016); and the development of organic farming concept in Bulgarian society for more than 35 years (Dimitrov, Ivanova 2017). All this activities led to the increase of organic consumers on national level following the general trend in Europe and in the world, which offer great opportunities for forward development of the sector.

Despite the obstacles, organic farming in Bulgaria is developing as a successful entrepreneurial initiative in rural regions (Nikolova 2012).

Production of organic foods is a specific part of the agricultural sector. The higher requirements for such enterprises on the technology and techniques they must employ in order for their production to be certified is better suited for young, flexible entrepreneurs that are prepared to modify their operations based on innovation. This is clearly evident when we analyze the employment of young Bulgarians in the country's agricultural sector (see Figure 1). The group of managers 
of agricultural productions under 35 years old forms just $16.3 \%$ of all managers in Bulgarian agriculture. Out of those more than $10 \%$ are involved in organic productions. The higher profit margins and the younger market for organic foods attracts younger entrepreneurs that are able to employ the government and EU wide funding opportunities to a larger degree.

\section{Figurate 1. Comparison of age distribution of farm managers in the organic and non-organic sector in the EU-28 in 2013}

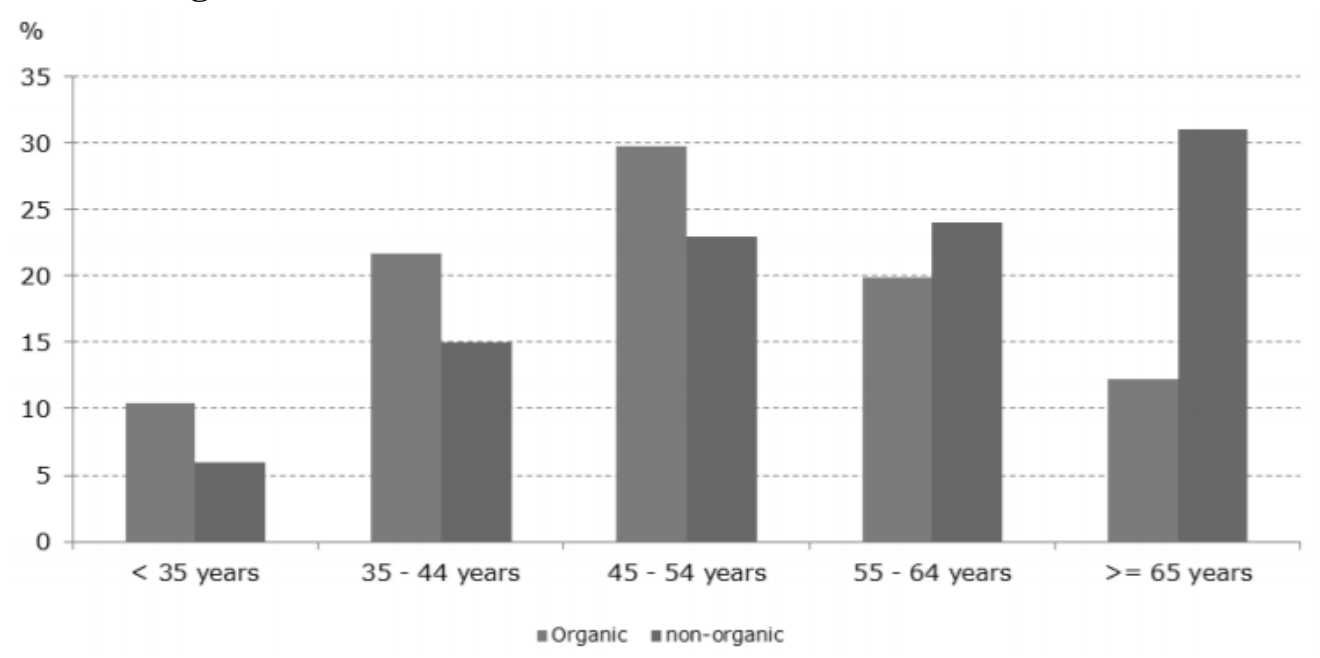

Source: Eurostat data FSS.

We have noticed the same trend when we conducted interviews with processors and merchants of organic foods. As part of the project "Production capacity and local consumption of organic products from livestock breeding in Southeast Region" funded by National Scientific Research Fund our research team has conducted numerous interviews with managers and employees from processing and marketing organizations from the sector and a very high percentage of them (more than 65\%) were from this age group (under 35 years old). This have lead us to the conclusion that this newly forming sector for organic food production, processing and sales creates unique opportunities for which younger entrepreneurs are better prepared.

Further research on impact of the undergoing development of organic food sector on youth employment is required in order to evaluate the specific motivation 
of young entrepreneurs and relevant policy adjustments that can address these new opportunities to increase the overall youth employment in Bulgarian agriculture.

\section{Conclusions}

Imported products have a very strong presence on Bulgarian market, at least $36 \%$ in 2015 , according to Euromonitor, and about $60 \%$ according to other sources of information on the industry. National producers cannot yet sufficiently identify the requirements of Bulgarian consumers and provide them with products that meet these requirements. Also of importance is the fact that customers tend to trust more internationally certified bio products than the local ones.

There is still not enough bio-food processing plants in the country and with the necessary capacity to meet the local market needs. This has led to a clear export orientation of local bio products. Over the last two years, the construction and certification of processing facilities in the sector have begun and they are most often the result of foreign investment. Adding value to Bulgarian bio products is important for their recognition and trust by local consumers as well as those on international markets.

The organic food market in Bulgaria is estimated at over BGN 30 million for 2016-2017 and is expected to reach levels of about 40 million by 2020. The role of foreign products on the national bio market is diminishing and by 2020 they are expected to represent less than $50 \%$, with their market share at the moment of about $60 \%$. These trends stimulate local producers to seek direct contact with consumers, mainly because of their difficult relationships with the retail chains and the complex processes of certification as well as the legitimacy of the latter. Consumers purchase mostly packaged organic foods and baby bio foods due to the clearly-labeled certification of these products.

The organic production sector, as a newly forming part of Bulgarian agricultural sector focused on organic food production, processing and sales creates unique opportunities for which younger entrepreneurs are better prepared. While the group of farmers under 35 years old makes up the same percentage of organic food 
producers as the group of 65 years and older, they are nearly six times less represented in the non-organic producers. This let us conclude that young farmers are more involved with organic farming than non-organic and this trend should continue in the future and thus create new opportunities for young people in Bulgaria.

This newly forming sector for organic food production, processing and sales creates unique opportunities for which younger entrepreneurs are better prepared. Our research result show that almost twice as many young managers are focused on the organic sub-sector than there are working with traditional methods. This correlation is only evident in the group of managers under 35 yours of age and can be used as an evidence for the impact of the development of the sector on youth employment via the opportunities it creates.

\section{Acknowledgments}

This research was established as a part of Project "Production capacity and local consumption of organic products from livestock breeding in Southeast Region" funded by National Scientific research fund and the Ministry of Science and Education of Republic of Bulgaria.

\section{References}

Balieva G.N., Huliyan M. (2015), Production and supply of regional food products - incentives and challenges for small holdings in Bulgaria, „International Journal of Science and Research”, vol. 4 no. 2 , pp. 576-580, http://www.ijsr.net/archive/v4i2/v4i2_01.php\#sthash.ablyMD1V.dpbs [31.05.2019].

Dimitrov K., Ivanova M. (2017), Trends in organic farming development in Bulgaria. Applying circular economy principles to sustainable rural development, ,Visegrad Journal on Bioeconomy and Sustainable Development", vol. 6 no. 1, pp. 10-16.

European Commission (2015), Rural development program of the Republic of Bulgaria 2014-2020. https://ec.europa.eu/agriculture/rural-development-2014-2020/country-files/bg_en [31.05.2019].

Eurostat Database, https://ec.europa.eu/eurostat.

FiBL, IFOAM (2015), The world of organic agriculture. Statistics and emerging trends, https://www.fibl.org/fileadmin/documents/shop/1663-organic-world-2015.pdf [31.05.2019].

Kostadinova P., Popov V. (2012), Basic principles and methods of organic agriculture, „New Knowledge", vol. 1 no. 3, pp. 58-65. 
Kristeva I. (2014), State and trends for the development of organic production in Bulgaria for the period 2006-2012. Reports from the Jubilee Conference „The National Agrarian Sector - Element of the European Agricultural Regions in the Europe 2020 Strategy", Tsenov, Svishtov, pp.179-184.

Ministry of Agriculture and Food of the Republic of Bulgaria (2017), Annual report on the situation and development of agriculture, http://www.mzh.government.bg/MZH/Libraries/Actual2/Annual report 2017 EN.sflb.ashx [31.05.2019].

Nikolova M. (2012), Organic production in Bulgaria - an innovative solution for creating entrepreneurial initiatives in rural regions, Scientific and applied international conference „Development of Agribusiness and Rural Regions in Bulgaria and EU perspectives 2020”, University of Economics, Varna, pp. 231-241.

Ordinance № 4 of 24.02.2015 on the implementation of Measure 11 „Organic farming” of the RDP for the period 2014-2020.

Rossi R. (2016), Facts and figures on organic agriculture in the European Union of European Commission, DG Agriculture and Rural Development, Unit Economic Analysis of EU Agriculture, http://ec.europa.eu/agriculture/rica/pdf/Organic_2016_web_new.pdf [31.05.2019].

Willer H., Lernoud J. (eds.) (2018), The world of organic agriculture. Statistics and emerging trends 2018, Research Institute of Organic Agriculture (FiBL), Frick, IFOAM - Organic International, Bonn. 